Available online: http://openjournal.wdh.ac.id/index.php/edudharma

Edu Dharma Journal: Jurnal Penelitian dan Pengabdian Masyarakat ISSN (Print) 2597-890 X , ISSN (Online) 2686-6366
$597-890 \times$ (media cetak $2686-6366$ (media online ARMA u r n a

\title{
HUBUNGAN PENGARUH TEMAN DENGAN FREKUENSI KONSUMSI FAST FOOD MODERN PADA MAHASISWA UNIVERSITAS XYZ DI KOTA DEPOK
}

\author{
Nur Putri Erdianti \\ Universitas Gunadarma Depok, Depok, City, West Java, Indonesia
}

\begin{tabular}{|c|c|}
\hline ARTICLE INFORMATION & ABSTRACT \\
\hline $\begin{array}{l}\text { Name: Nur Putri Erdianti } \\
\text { E-mail: } \\
\text { erdeeanti.nurputri@gmail.com }\end{array}$ & \multirow{2}{*}{$\begin{array}{l}\text { Excessive consumption of fast food can increase the incidence of obesity and } \\
\text { other health problems in adolescents. Eating fast food more than twice per } \\
\text { week can increase BMI z-score significantly, compared to eating fast food once } \\
\text { a week or not eating fast food at all. This study aims to determine the } \\
\text { relationship between the influence of friends with the frequency of modern fast } \\
\text { food consumption among students XYZ University in Depok. The research } \\
\text { method used is quantitative with cross-sectional study design conducted to } 148 \\
\text { students XYZ University Depok selected by systematic random sampling. It used } \\
\text { questionnaire about individual characteristics, food characteristics, and } \\
\text { environmental characteristics, while data of frequency fast food consumption } \\
\text { from FFQ. Result showed that } 51,4 \% \text { of respondents consumed fast food often. } \\
\text { Furthermore, there is a difference proportion in the influence of friends ( } p= \\
\text { o.001) in determining the frequency of fast food consumption. Students with } \\
\text { strong friend influences are } 3.6 \text { times more likely to eat fast food more often } \\
\text { compared to poor friend influences. }\end{array}$} \\
\hline $\begin{array}{l}\text { Keywords: (3-5 words or phrase) } \\
\text { Fast food consumption_1 } \\
\text { Friend influence_2 } \\
\text { College student_3 }\end{array}$ & \\
\hline $\begin{array}{l}\text { Kata Kunci: (3-5 kata atau } \\
\text { frase) } \\
\text { Konsumsi fast food _1 } \\
\text { Pengaruh teman_2 } \\
\text { Mahasiswa_3 }\end{array}$ & $\begin{array}{l}\text { Konsumsi fast food yang berlebihan dapat meningkatkan kejadian obesitas dan } \\
\text { masalah kesehatan lainnya pada remaja. Mengonsumsi fast food lebih dari dua } \\
\text { kali per minggu dapat meningkatkan BMI Z-score secara signifikan, } \\
\text { dibandingkan dengan yang mengonsumsi fast food seminggu sekali atau tidak } \\
\text { mengonsumsi fast food sama sekali. Penelitian ini bertujuan untuk mengetahui } \\
\text { hubungan faktor pengaruh teman dengan frekuensi konsumsi fast food modern } \\
\text { pada mahasiswa Universitas XYZ di Kota Depok. Metode penelitian yang } \\
\text { digunakan adalah kuantitatif dengan desain studi cross-sectional yang } \\
\text { dilakukan kepada } 148 \text { mahasiswa Universitas XYZ yang dipilih dengan } \\
\text { systematic random sampling. Data karakteristik diperoleh dari kuesioner, } \\
\text { sedangkan data frekuensi konsumsi fast food diperoleh dari FFQ. Hasil } \\
\text { penelitian ini menunjukkan sebanyak } 51,4 \% \text { responden mengonsumsi fast food } \\
\text { dengan frekuensi sering. Terdapat perbedaan proporsi pada pengaruh teman } \\
\text { (p=0,001) dalam menentukan frekuensi konsumsi fast food. Mahasiswa dengan } \\
\text { pengaruh teman yang kuat berpeluang } 3,6 \text { kali lebih sering mengonsumsi fast } \\
\text { food dibandingkan mahasiswa dengan pengaruh teman lemah. }\end{array}$ \\
\hline
\end{tabular}




\section{PENDAHULUAN}

Fast food adalah suatu jenis makanan yang disajikan secara cepat dan cenderung memiliki kepadatan energi yang tinggi, atau dapat dikatakan tinggi kalori (Brindal, 2010). Definisi lain dari fast food yaitu makanan dan/atau minuman yang sudah diolah dan siap untuk langsung disajikan di tempat usaha atau di luar tempat usaha atas dasar pesanan (Kemenkes RI, 2013). Konsumsi fast food yang berlebihan dapat meningkatkan kejadian obesitas dan masalah kesehatan lainnya pada remaja (WHO, 2016; Anderson et al., 2011; Garcia et al., 2012).

Tingginya frekuensi konsumsi fast food berdampak pada rendahnya kualitas diet dan kejadian overweight serta obesitas, yang dapat menimbulkan penyakit degeneratif seperti $44 \%$ orang menderita diabetes, $23 \%$ orang menderita penyakit jantung iskemik dan $7-41 \%$ orang menderita kanker tertentu (WHO, 2016). Penelitian kohort selama 15 tahun di Amerika menunjukkan bahwa mengonsumsi fast food lebih dari dua kali per minggu beresiko mengalami kenaikan berat badan sebesar $4,5 \mathrm{~kg}$ dan beresiko mengalami resistensi insulin sebesar 104\% lebih besar (Pereira, 2005). Penelitian lain menemukan bahwa mengonsumsi fast food lebih dari dua kali per minggu dapat meningkatkan BMI z-score secara signifikan, dibandingkan dengan yang mengonsumsi fast food seminggu sekali atau tidak mengonsumsi fast food sama sekali (Thompson, 2004).

Faktor yang memengaruhi perilaku pemilihan makanan yaitu karakteristik individu, karakteristik makanan dan karakteristik lingkungan (Suhardjo 1989). Karakteristik individu yang mempengaruhi konsumsi fast food antara lain jenis kelamin (Dave et al., 2009; Van Zyl et al., 2010; Longacre, 2012; Marhamah et al., 2013) dan pengetahuan gizi (Vidya \& Rao, 2006; Mirsanjari et al., 2012). Sedangkan karakteristik lingkungan yang mempengaruhi konsumsi fast food yaitu tempat tinggal (Harris et al., 2006; Kremmyda et al., 2008; El Ansari et al., 2012), waktu makan (Anderson et al., 2011; Vaida, 2013; Putri, 2016), jarak restoran fast food (Kwate \& Loh, 2010; Sharkey et al., 2011; Forsyth et al., 2012), dan pengaruh teman (Brown, 2010; Seo et al., 2011).

Depok, sebagai salah satu kota penyangga Jakarta, mengalami perkembangan yang cukup pesat. Perekonomian Kota Depok yang semakin meningkat dapat dilihat dari semakin banyaknya sentra yang bermunculan, seperti restoran, mall, serta tempat-tempat usaha lainnya, yang sejalan dengan berkembangnya restoran ataupun geraigerai fast food. Universitas XYZ, salah satu universitas yang berada di Kota 
Depok, adalah kampus yang berlokasi di pusat Kota Depok, yang dikelilingi oleh banyak restoran/gerai fast food. Berdasarkan survei pendahuluan, terdapat dua restoran fast food dengan jarak hanya $1 \mathrm{~m}$ dari kampus, dan beberapa kios yang menjual fast food yang berjarak kurang dari 10m dari kampus. Hal-hal tersebut membuat peneliti ingin mengetahui faktor yang berhubungan dengan konsumsi fast food modern pada mahasiswa Universitas XYZ, Kota Depok.

\section{METODE}

Penelitian ini dilakukan pada bulan Mei 2019 menggunakan pendekatan kuantitatif dengan desain studi cross sectional. Populasi pada penelitian ini adalah mahasiswa $\mathrm{S} 1$ reguler Universitas XYZ Fakultas Ilmu Komputer dan Teknologi Informasi yang melaksanakan perkuliahan di Kampus Kelapa Dua Depok, Jawa Barat. Lokasi penelitian dipilih karena aksesibilitas yang tinggi, ditandai dengan banyaknya restoran fast food yang dekat dan mudah dijangkau, sehingga mudah untuk memperoleh fast food di lokasi tersebut.

Kriteria inklusi pada penelitian ini adalah mahasiswa Fakultas Ilmu Komputer dan Teknologi Informasi yang melaksanakan perkuliahan di Kampus Universitas XYZ Kelapa Dua, Depok, Jawa Barat pada bulan penelitian dilakukan, minimal 1 hari dalam 1 minggu jadwal perkuliahan dan berada dalam keadaan sehat fisik dan mental. Setelah dilakukan penghitungan besar sampel dengan rumus uji hipotesis beda proporsi untuk two tail, didapatkan jumlah sampel sebesar 148 mahasiswa.

Pengumpulan data dilakukan dengan menggunakan kuesioner, Food Frequency Questionnaire (FFQ), sedangkan jarak restoran dengan kampus diketahui melalui observasi lapangan dan diukur menggunakan pencitraan satelit dengan bantuan perangkat lunak Google Maps Geo-Coding JavaScript API versi 3.0.

Pengumpulan data primer dilakukan dengan bantuan instrumen penelitian. Instrumen yang digunakan dalam penelitian adalah kuesioner, yang digunakan untuk mengumpulkan seluruh data variabel yang diteliti. Kuesioner yang diisi sendiri oleh responden terdiri dari dua bagian. Bagian pertama adalah kuesioner yang berisi pertanyaan untuk mendapatkan gambaran mengenai karakteristik responden, jenis kelamin, pengetahuan gizi, tempat tinggal, waktu makan, jarak restoran, dan pengaruh teman. Data mengenai jarak restoran diperoleh dengan cara menghubungkan titik lokasi universitas dengan titik restoran fast food yang dikunjungi oleh responden. Kuesioner bagian kedua adalah Food 
Frequency Questionnaire (FFQ) yang digunakan untuk menilai frekuensi makanan yang dikonsumsi selama periode waktu tertentu. Kedua kuesioner yang digunakan dikumpulkan pada hari yang sama.

Untuk mendapatkan data berupa jarak kampus terhadap restoran fast food, peneliti akan melakukan observasi lapangan terlebih dahulu, kemudian digunakan instrumen perangkat lunak Google Maps Geo-Coding JavaScript API Versi 3.0 untuk mengetahui jarak kampus terhadap restoran fast food yang dikunjungi. Data yang didapat akan ditulis dalam sebuah form untuk memudahkan skoring.

Uji statistik yang digunakan pada penelitian ini adalah chi square test karena variabel dependen dan independen yang ada dalam penelitian ini bersifat kategorik.

\section{HASIL}

\section{Frekuensi Konsumsi Fast Food}

Frekuensi konsumsi fast food pada mahasiswa Universitas XYZ menunjukkan bahwa sebanyak $51,4 \%$ responden berada pada kategori sering ( $\geq 3 \mathrm{x} /$ minggu) dan 48,6\% lainnya berada pada kategori jarang $(<3 \mathrm{x}$ /minggu). Jumlah minimum frekuensi konsumsi fast food dalam seminggu pada satu bulan terakhir adalah tidak pernah (0), median sebanyak 3 kali, dan jumlah maksimum 8 kali dalam seminggu.

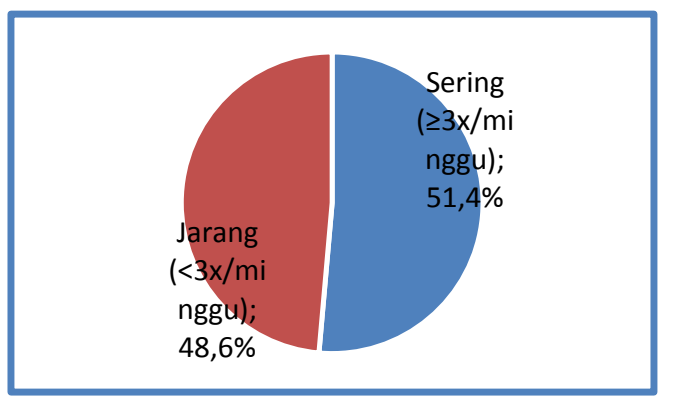

Gambar 1. Frekuensi Konsumsi Fast Food

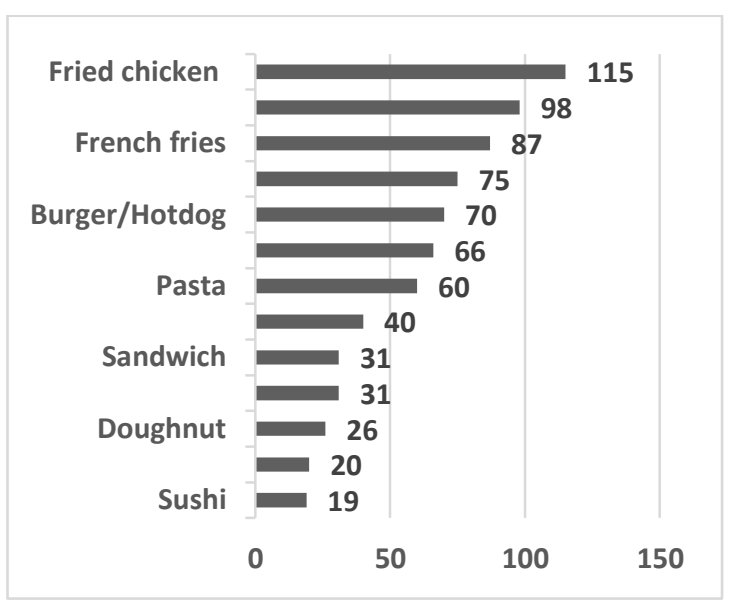

Gambar 2 Jenis Fast Food yang Paling Disukai

Jenis fast food yang paling disukai oleh mahasiswa adalah fried chicken, dilanjutkan dengan pizza, french fries, kebab dan burger.

\section{Analisis Karakteristik Individu}

Karakteristik individu terdiri dari variabel jenis kelamin dan pengetahuan gizi. Pada variabel jenis kelamin, mahasiswa perempuan $(51,4 \%)$ lebih banyak daripada laki-laki. Pada variabel pengetahuan gizi, mahasiswa dengan 
pengetahuan gizi kurang $(76,4 \%)$ lebih gizi baik. Data selengkapnya dapat dilihat besar dibandingkan dengan pengetahuan pada tabel 1.

Tabel 1. Karakteristik Individu

\begin{tabular}{|c|c|c|}
\hline Variabel & $\mathrm{n}$ & $\%$ \\
\hline 1. Jenis Kelamin & & \\
\hline Laki-laki & 72 & 48,6 \\
\hline Perempuan & 76 & 51,4 \\
\hline Total & 148 & 100 \\
\hline 2. Pengetahuan Gizi & & \\
\hline Kurang & 113 & 76,4 \\
\hline Baik & 35 & 23,6 \\
\hline Total & 148 & 100 \\
\hline
\end{tabular}

\section{Analisis Karakteristik Lingkungan}

Karakteristik lingkungan terdiri dari variabel tempat tinggal, waktu makan, jarak restoran, dan pengaruh teman. Pada variabel tempat tinggal, mahasiswa yang bertempat tinggal dengan orang tua $(71,6 \%)$ lebih besar. Pada variabel waktu makan dibagi menjadi tiga kategori yaitu makan pagi, makan siang, dan makan malam. Hasil menunjukkan mahasiswa yang termasuk dalam waktu makan siang $(48,6 \%)$ lebih besar daripada waktu makan lainnya. Variabel jarak restoran fast food dikategorikan menjadi dua, yaitu jarak dekat apabila $\leq 800 \mathrm{~m}$ dari lokasi kampus dan jarak jauh apabila $>800 \mathrm{~m}$ dari lokasi kampus. Hasil yang didapatkan adalah mahasiswa yang berada dalam kategori jarak restoran dekat $(69,6 \%)$ lebih besar. Variabel pengaruh teman dibagi menjadi dua kategori, yaitu pengaruh kuat dan pengaruh lemah. Hasil menunjukkan bahwa mahasiswa yang berada dalam pengaruh teman yang kuat $(54,7 \%)$ lebih. 
Tabel 2. Karakteristik Lingkungan

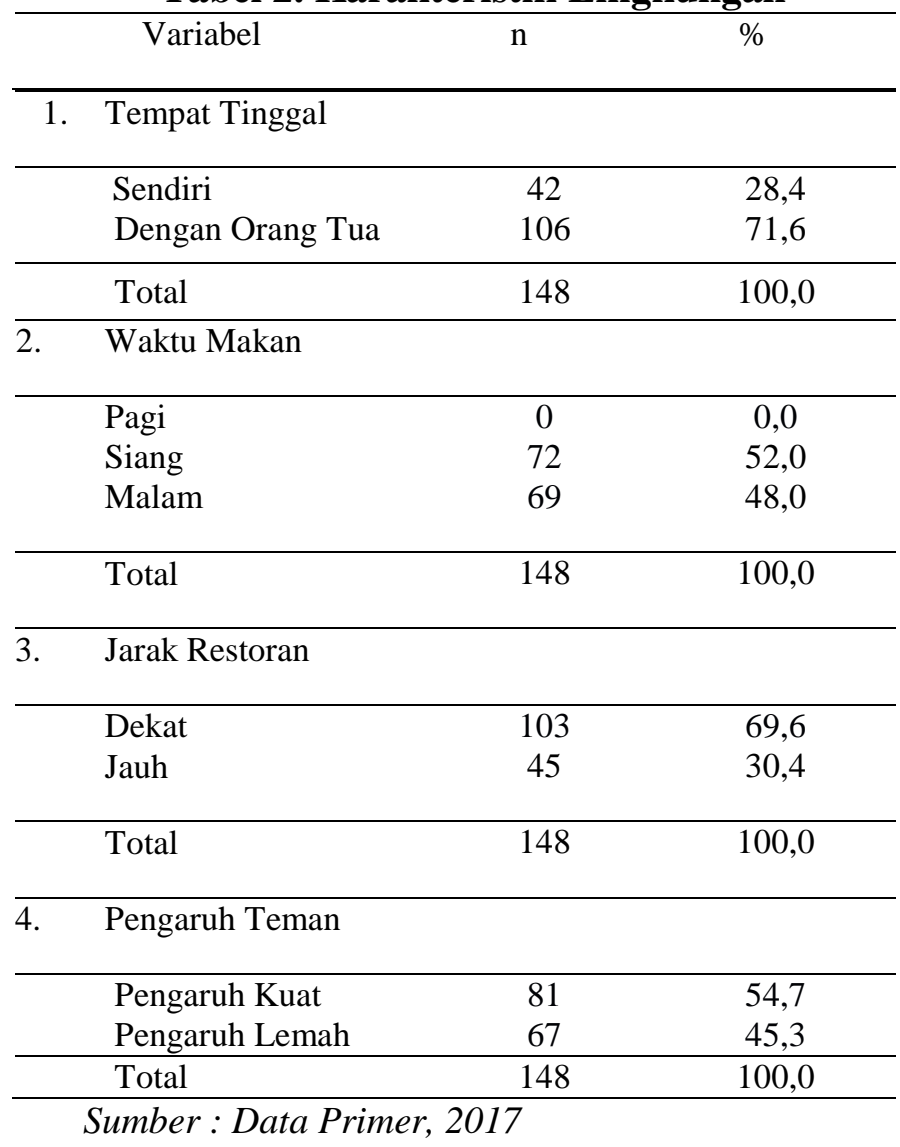

Sumber : Data Primer, 2017

\section{Hubungan Pengaruh Teman dengan Frekuensi Konsumsi Fast Food}

Tabel 3. Hubungan Pengaruh Teman dengan Frekuensi Konsumsi Fast Food pada Mahasiswa Universitas XYZ

\begin{tabular}{|c|c|c|c|c|c|c|c|c|}
\hline \multirow{3}{*}{ Pengaruh Teman } & \multicolumn{4}{|c|}{ Frekuensi Konsumsi Fast Food } & \multirow{2}{*}{\multicolumn{2}{|c|}{ Total }} & \multirow{3}{*}{$\begin{array}{c}\text { p } \\
\text { Value }\end{array}$} & \multirow{3}{*}{$\begin{array}{c}\text { OR } \\
95 \% \text { CI }\end{array}$} \\
\hline & \multicolumn{2}{|c|}{ Sering } & \multicolumn{2}{|c|}{ Jarang } & & & & \\
\hline & $\mathbf{n}$ & $\%$ & $\mathbf{n}$ & $\%$ & $\mathbf{n}$ & $\%$ & & \\
\hline Pengaruh Kuat & 53 & 65,4 & 28 & 34,6 & 81 & 100 & 0,001 & 3,621 \\
\hline Pengaruh Lemah & 23 & 34,3 & 44 & 65,7 & 67 & 100 & & $(1,832-$ \\
\hline Total & 76 & 51,4 & 72 & 48,6 & 148 & 100 & & $7,156)$ \\
\hline
\end{tabular}

Hasil analisis hubungan antara pengaruh teman dengan frekuensi konsumsi fast food diperoleh bahwa ada sebanyak $(65,4 \%)$ mahasiswa yang pengaruh teman kuat mengonsumsi fast food sering. Hasil uji statistik diperoleh nilai $\mathrm{p}=0,001$, maka dapat disimpulkan ada perbedaan proporsi pada pengaruh teman dalam menentukan frekuensi konsumsi fast food. Data selengkapnya dapat dilihat pada tabel 3 . 


\section{PEMBAHASAN}

Berdasarkan penelitian yang telah dilakukan, didapati bahwa $51,4 \%$ atau lebih dari setengah mahasiswa Universitas XYZ mengonsumsi fast food dalam frekuensi sering, yaitu sebanyak lebih dari $3 \mathrm{x}$ dalam waktu seminggu. Frekuensi konsumsi fast food maksimum adalah sebanyak $8 \mathrm{x}$ dalam seminggu atau bisa dikatakan bahwa responden mengonsumsi fast food setiap hari dalam seminggu. Jika dibandingkan dengan penelitian lainnya, penelitian pada remaja di Minessota menunjukkan hasil yang sedikit lebih tinggi dengan penelitian ini, yaitu sebanyak 57,5\% responden mengonsumsi fast food lebih dari 3x seminggu (Bauer, 2009). Begitu juga dengan penelitian pada siswa SMA di Kabupaten Tangerang, didapatkan hasil yang agak sedikit lebih tinggi juga pada kategori frekuensi konsumsi fast food sering ( $\geq 3 \mathrm{x} /$ minggu) yaitu sebesar 54,6\%, namun nilai maksimum frekuensi konsumsi fast food maksimumnya adalah sebesar 5x dalam seminggu (Pascaramadhani, 2014), lebih rendah dari penelitian ini. Pada penelitian pada mahasiswa UI di Depok, didapatkan hasil sedikit lebih rendah pada kategori frekuensi konsumsi fast food sering (>3x/minggu) yaitu sebesar $48,0 \%$, namun nilai maksimum frekuensi konsumsi fast food maksimumnya adalah sebesar 10,5x dalam seminggu (Putri, 2016), lebih tinggi dari penelitian ini. Frekuensi tersebut dapat terjadi karena pada penelitian ini kios/restoran yang menjual fast food di sekitar lingkungan kampus berada pada jarak yang cukup dekat dengan kampus, $<200$ m dari lokasi kampus sudah terdapat restoran fast food.

Jenis fast food yang paling sering dikonsumsi adalah fried chicken, diikuti oleh french fries, burger, pizza, dan pasta (gambar 2.). Penelitian pada remaja SMA di Tangerang Kota (Surya, 2013) dan penelitian pada remaja SMA di Kabupaten Tangerang (Pascaramadhani, 2014) juga mendapatkan hasil yang sama, jenis fast food yang paling sering dikonsumsi oleh respondennya adalah fried chicken. Fried chicken menjadi jenis fast food yang paling sering dikonsumsi responden adalah wajar terjadi karena di dekat kampus terdapat restoran Richeese Factory (150m) dan restoran $\mathrm{McD}$ (200m), dimana restoran fast food tersebut menjual fried chicken sebagai menu utamanya.

Variabel pengaruh teman dibagi menjadi dua kategori, yaitu pengaruh kuat dan pengaruh lemah. Berdasarkan hasil penelitian didapati bahwa 54,7\% responden berada dalam pengaruh teman yang kuat, lebih besar daripada responden yang berada dalam pengaruh teman yang lemah. Hasil analisis hubungan antara pengaruh teman dengan frekuensi konsumsi fast food diperoleh bahwa 
sebanyak $65,4 \%$ responden yang pengaruh teman kuat mengonsumsi fast food sering, dengan nilai $\mathrm{p}=0,002$ dan nilai $\mathrm{OR}=$ 3,621 , artinya responden dengan pengaruh teman kuat mempunyai peluang 3,6 kali untuk mengonsumsi fast food sering dibandingkan responden dengan pengaruh teman lemah.

Penelitian ini sejalan dengan penelitian Seo et al. (2011) yang mendapatkan bahwa konsumsi fast food pada remaja sangat berhubungan dengan pengaruh teman. Hal ini mungkin berkaitan dengan responden pada penelitian yang menjawab bahwa mereka mengonsumsi fast food pada hari-hari yang spesial $(33,9 \%)$ atau bertemu/berkumpul dengan teman-teman lain (25,7\%). Penelitian ini sesuai juga dengan penelitian Story et al. (2002), bahwa remaja menghabiskan waktu paling banyak dengan teman-temannya dan makan adalah bentuk penting dalam bersosialisasi. Berdasarkan teori, bahwa semakin matangnya remaja, mereka akan semakin mengurangi waktu dengan keluarga dan sebaliknya lebih banyak waktu dengan peer group. Makan di luar menjadi lazim dilakukan, misalnya pada remaja perempuan, sebanyak 1/3 makanan yang mereka makan diperoleh dari makan di luar rumah dan rata-rata remaja makan pada restoran fast food minimal dua kali seminggu dengan alasan untuk dapat berinteraksi sosial dengan peer group (Brown, 2010). Teman sebaya atau peer group memang memegang peranan penting dalam menentukan perilaku pada remaja, terutama ramaja pertengahan (Steinburgh, 1996).

Adapun jika dihubungkan dengan jenis kelamin, pengaruh teman yang lebih kuat berasal dari jenis kelamin perempuan yaitu sebesar 50,6\%. Artinya pengaruh teman perempuan mempunyai pengaruh yang lebih besar dalam menentukan frekuensi konsumsi fast food dibandingkan pengaruh teman laki-laki, walaupun secara signifikan tidak terdapat hubungan antara pengaruh teman dengan jenis kelamin.

Interaksi terhadap teman yang cukup tinggi pada penelitian ini bisa terjadi karena ikatan pertemanan yang sudah terjalin selama masa perkuliahan mereka ditempatkan berada pada satu kelas yang sama pada setiap perkuliahan yang ada. Tidak mengherankan maka hubungan pertemanan antar mahasiswa akan terjalin cukup kuat dan dapat memengaruhi berbagai macam hal dalam kehidupan seseorang, termasuk juga dalam hal konsumsi makanan khususnya konsumsi fast food.

\section{KESIMPULAN}

Pengaruh teman berhubungan dengan frekuensi konsumsi fast food mahasiswa Universitas XYZ di Depok. 
Mahasiswa yang mendapatkan pengaruh teman kuat berpeluang 3,6 kali lebih sering mengonsumsi fast food dibandingkan mahasiswa yang mendapatkan pengaruh teman lemah.

\section{DAFTAR PUSTAKA}

Anderson B, Rafferty AP, Lyon-Callo S, Fussman C, Imes G. Fast-food consumption and obesity among Michigan adults. Prev Chronic Dis 2011;8(4):A71.

Bauer, K.W., Larson, N.I., Nelson, M.C., et al. Fast food intake among adolescents: secular and longitudinal trends from 1999 to 2004. American Journal of Preventive Medicine. 2009. 48: 284-287.

Brindal, Emily. Exploring Fast Food Consumption Behaviours and Social Influence. Faculty of Health Science, the University of Adelaide,.South Australia. 2010.

Brown, J.E. Nutrition throught the life cycle. Fourth edition. W adsworth. California. 2010.

Dave, Jayna M., Lawrence C An, Robert W Jeffery, \& Jasjit S.A. Relationship of Attitudes Toward Fast Food and
Frequency of Fast-food Intake in Adults. Obesity. 2009. 17: 1164-1170.

El Ansari, W., Stock, C., \& Mikolajczyk, R. T. Relationships between food consumption and living arrangements among university students in four European countries - A cross-sectional study. Nutrition Journal. 2012. 11: 28.

Forsyth, A., Wall, M., Larson, N., Story, M., \& Dianne, N-S. Do adolescent who live or go to school near fast food restaurant eat more frequently from fast food restaurant? Journal of Health and Place. 2012. 18: 1261-1269.

Garcia, G., Sunil, T.S. \& Hinojosa, P. The Fast Food and Obesity Link: Consumption Patterns and Severity of Obesity. OBES SURG .2012. 22: 810.

Harris KM, Gordon-Larsen P, Chantala K, Udry JR. Longitudinal trends in race/ethnic disparities in leading health indicators from adolescence to young adulthood. Arch Pediatr Adolesc Med. 2006. 160:74-81.

Kementerian Kesehatan, R.I. Peraturan Menteri Kesehatan Republik Indonesia Nomor 30 Tahun 2013 Tentang Pencantuman Informasi Kandungan Gula, Garam, Dan Lemak 
Serta Pesan Kesehatan Untuk Pangan

Olahan Dan Pangan Siap Saji. Jakarta. 2013.

Kremmyda LS, Papadaki A, Hondros G, Kapsokefalou M, Scott JA. Differentiating between the effect of rapid dietary acculturation and the effect of living away from home for the first time, on the diets of Greek students studying in Glasgow. Appetite. 2008. 50:455-463.

Kwate, N.O.A., \& Loh, J.M. Separate and unequal: the influence of neighborhood and school characteristic on spatial proximity between fast food and schools. Journal of Preventive Medicine. 2010. 51: $153-156$.

Longacre, M.R. et al. Fast-food environments and family fast-food intake in nonmetropolitan areas. American Journal of Preventive Medicine. 2012. 42 (6): 579-587.

Marhamah, Ron Makrony, Eko Yuliastuti. Analisis Faktor-Faktor Dominan Yang Mempengaruhi Keputusan Remaja Untuk Mengonsumsi Makanan Fast Food. Penelitian Dosen Pemula, Universitas Terbuka. 2013.
Mirsanjari, Mitra, et al. Relationship between nutritional knowledge and healthy attitude and practice during pregnancy. Borneo science. 2012. 31.

Pascaramadhani, Addini. Faktor dominan frekuensi konsumsi fast food siswa SMA Islamic Village tahun 2014. Skripsi Fakultas Kesehatan Masyarakat, Universitas Indonesia. 2014.

Pereira, M. A, A. I. Kartashov, C. B. Ebbeling, L.Van Horn, M. L. Slattery, D. R. Jacobs Jr., and D. S. Ludwig. Fast-Food Habits, Weight Gain, and Insulin Resistance (The CARDIA Study): 15-Year Prospective Analysis. The Lancet. 2005. 365(9453): 36-42.

Putri, Nabila Marsya Syaihu. Faktor dominan frekuensi konsumsi fast food pada mahasiswa FISIP UI tahun 2016. Skripsi Fakultas Kesehatan Masyarakat, Universitas Indonesia. 2016.

Seo, H., Lee, S.-K., \& Nam, S. Factors influencing fast food consumption behaviors of middle-school students in Seoul: an application of theory of planned behaviors. Nutrition Research and Practice. 2011. 5(2): 169-178. 
Sharkey, Joseph R, Johnson, Cassandra M., Wesley R, Dean, \& Horel, Scott A. Association between proximity to and coverage of traditional fast- food restaurants and nontraditional fastfood outlets and fast-food consumption among rural adults. International Journal of Health Geographics. 2011. 10: 37.

Steinburg L. Adolescence. McGraw-Hill. New York. 1996.

Story, M., Neumark-Sztainer, D., \& French, S. Individual and environmental influences on adolescent eating behaviors. American Journal of Diet Association. 2002. 102: S40-S51.

Suhardjo. Sosio Budaya Gizi. Bogor: IPB PAU Pangan dan Gizi. 1989.

Surya, Ade Permata. Faktor Dominan dalam Menentukan Frekuensi Konsumsi Fast Food Modern pada Siswa-Siswi SMA Negeri di Kecamatan Tangerang Kota, Kota Tangerang Tahun 2013. Skripsi Fakultas Kesehatan Masyarakat, Universitas Indonesia. 2013.

Thompson, O. M., Ballew, C., Resnicow, L., Must, A., Badini, L. G., Cyr, H., \&
Dietz, W. H. Food purchased away from home as a predictor of change in BMI z-score among girls. International Journal of Obesity. 2004. 28: 282-289.

Vaida, Naheed. Prevalence of Fast Food Intake among Urban Adolescent Students. The International Journal of Engineering and Science. 2013. 2 (1): 353-359.

Van Zyl, MK, Steyn NP, Marais ML. Characteristics and factors influencing fast food intake of young adult costumers in Johannesburg, South Africa. S Afr J Clin Nutr. 2010. 23 (3): 124-130.

Vidya, Chintapalli, \& Bhaskara Rao. A textbook of nutrition. Discovery Publishing House. New Delhi. 2006.

WHO. Obesity. http://www.who.int/mediacentre/facts heets/fs311/en/. 2019. 